\title{
A Gas Sensing Approach to Gain Insight into the Mechanism of DeNOx-SCR over Fe-ZSM-5 Catalysts
}

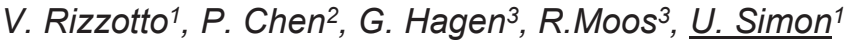 \\ ${ }^{1}$ RWTH Aachen University, Landoltweg 1a, 52074 Aachen, Germany \\ 2 South China University of Technology, 510006 Guangzhou, China \\ ${ }^{3}$ University of Bayreuth, 95440 Bayreuth, Germany \\ ulrich.simon@ac.rwth-aachen-de (U.S.)
}

\begin{abstract}
:
In order to meet the legislative emission requirements for $\mathrm{NO}_{x}$ emission, selective catalytic reduction (DeNOx-SCR) catalysts, in particular zeolites, are used. To improve their catalytic performance, an in-depth understanding of the reaction mechanisms is required based on an analysis of the physicochemical properties, preferably in situ. We introduce a setup combining impedance spectroscopy (IS) and infrared spectroscopy in diffuse reflection mode (DRIFT) for in situ measurements on zeolites under SCR-related conditions. By means of this gas sensing approach, we observed the formation of ammonium ion $\left(\mathrm{NH}_{4}^{+}\right)$intermediates resulting from the interaction of $\mathrm{NO}$ and $\mathrm{NH}_{3}$ on Fe-ZSM- 5 catalysts. The formed $\mathrm{NH}_{4}{ }^{+}$intermediates, indicating the activation of $\mathrm{NO}$ in the presence of adsorbed $\mathrm{NH}_{3}$, were found to correlate to the $\mathrm{NH}_{3}-\mathrm{SCR}$ activity of Fe-ZSM- 5 catalysts at low temperatures. These findings, which are not easily achievable by conventional methods, provide new and important perspectives to understand mechanistically the $\mathrm{NH}_{3}-\mathrm{SCR}$ reaction over Fe-zeolite catalysts.
\end{abstract}

Key words: Impedance spectroscopy, DRIFTS, $\mathrm{NH}_{3}-\mathrm{SCR}$ mechanism, proton transport, Fe-ZSM-5.

\section{Introduction}

One key strategy to reduce nitrogen oxides $\left(\mathrm{NO}_{\mathrm{x}}\right)$ emissions from lean-burn engines is the selective catalytic reduction using $\mathrm{NH}_{3}$ as reducing agent (DeNOx-SCR). Among the catalysts employed, metal-exchanged zeolites are the most widely used. Particularly, Fe-exchanged ZSM-5 zeolite demonstrated SCR activity in a wide temperature range and thermal durability under operative conditions [1]. At the same time, proton conducting zeolites are well known sensing materials for $\mathrm{NH}_{3}$ detection [2]. The stringent legislative emissions requirements require further improvement of SCR catalysts driven by an advanced mechanistic understanding of the catalytic cycle. In this context impedance spectroscopy (IS) in combination diffusereflection infrared Fourier transform spectroscopy (DRIFTS) applied in situ allowed us to gain important and unique information on the catalytic properties of Fe-ZSM-5.

\section{Combining IS and DRIFTS}

IS data are represented in an Arrhenius plot (Fig. 1a), that shows the temperature dependent proton conductivity. $\mathrm{NH}_{3}$-loaded Fe-
ZSM- 5 shows a higher proton conductivity then the pristine one below $350{ }^{\circ} \mathrm{C}$ due to the support of the adsorbed $\mathrm{NH}_{3}$ to the proton transport [2]. Performing measurements under different gas conditions, it was possible to individuate a temperature range $\left(175-250^{\circ} \mathrm{C}\right)$ in which the proton conductivity under $\mathrm{NO} / \mathrm{O}_{2}$ (SCR-related conditions) decreases much faster than under $\mathrm{N}_{2}$ (i.e. due to pure $\mathrm{NH}_{3}$ desorption). These results allow us to identify the interval in which $\mathrm{NH}_{3}$ is consumed by $\mathrm{SCR}$, and, therefore, in which the main information about SCR can be derived.
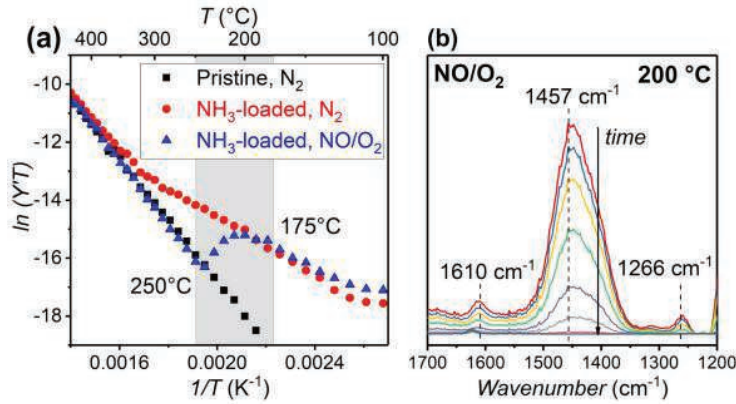

Fig. 1. Arrhenius plots for pristine and $\mathrm{NH}_{3}$-loaded Fe-ZSM-5 under different gas conditions (a); Time-resolved in situ DRIFT spectra of $\mathrm{NH}_{3}$-loaded $\mathrm{Fe}-\mathrm{ZSM}-5$ in $\mathrm{NO} / \mathrm{O}_{2}$ at $200{ }^{\circ} \mathrm{C}$ (b). 
Fig. 1b depicts the time-resolved spectra obtained for $\mathrm{NH}_{3}$-loaded Fe-ZSM-5, during exposure to $\mathrm{NO} / \mathrm{O}_{2}$ atmosphere centered in the "SCR temperature interval" $\left(200{ }^{\circ} \mathrm{C}\right)$. Thereby we observe the progressive consumption of $\mathrm{NH}_{3}$ following the decrease in intensity of the characteristic bands, associated to $\mathrm{NH}_{3}$ on $\mathrm{Fe}$ sites $\left(1266 \mathrm{~cm}^{-1}\right)$, on Lewis sites $\left(1610 \mathrm{~cm}^{-1}\right)$ and on Brønsted sites $\left(1457 \mathrm{~cm}^{-1}\right)$ [3]. Thanks to the IS-DRIFTS setup already described elsewhere [4], similar experiments under SCR conditions can be combined with single-frequency IS measurements, obtaining combined plots as shown in Fig. 2a-b. Here $\mathrm{NH}_{3}$-loaded Fe-ZSM-5 was exposed to $\mathrm{NO} / \mathrm{O}_{2}$ only after an interval under $\mathrm{N}_{2}$ or NO (Fig. 2a and $2 b$, respectively). In both situations, the proton conductivity (Is) seems to be strongly correlated to the $1457 \mathrm{~cm}^{-1}$ DRIFTS signal, attributed to $\mathrm{NH}_{4}{ }^{+}$ions formed on the Brønsted sites. Interestingly, both lis and DRIFTS intensity, experienced a slight increase in $\mathrm{NO} / \mathrm{O}_{2}$ after exposure to $\mathrm{N}_{2}$ (Fig. 2a). In contrast, this evolutionary trend is not observed, when the catalyst is exposed first to NO before applying $\mathrm{NO} / \mathrm{O}_{2}$. Furthermore, under $\mathrm{NO}$, the catalyst shows a significantly higher $\mathrm{I}_{\mathrm{IS}}$ signal compared to the measurement under $\mathrm{N}_{2}$ (Fig. $2 b)$. These results show that the co-adsorption and interaction of $\mathrm{NH}_{3}$ and $\mathrm{NO}$ on the $\mathrm{Fe}$ (III) sites leads to the formation of supplementary $\mathrm{NH}_{4}{ }^{+}$ions, suggesting that a mechanism similar to the redox cycle in Cu-exchanged zeolites [5] is followed: during the reduction of $\mathrm{Fe}(\mathrm{III})$ to $\mathrm{Fe}(\mathrm{II})$, a proton is generated on the adjacent Brønsted site, that, interacting with adsorbed $\mathrm{NH}_{3}$, leads to the formation of an $\mathrm{NH}_{4}{ }^{+}$ intermediate.
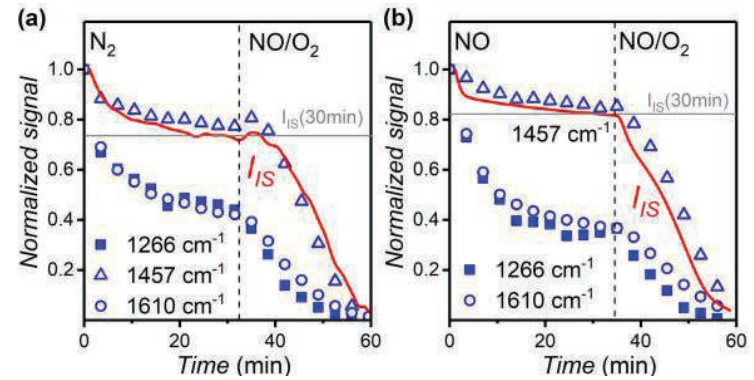

Fig. 2. Normalized ion conductivity signal (IIs, red line) and DRIFTS signal at characteristic wavenumbers (blue symbols) of $\mathrm{NH}_{3}$-loaded Fe-ZSM-5 exposed to different gas atmospheres at $175{ }^{\circ} \mathrm{C}$. The horizontal black line highlights the I/s values after 30 minutes, used to calculate $\Delta l_{I} s$. (adapted from [6])

\section{IS-DRIFTS and $\mathrm{NH}_{3}$-SCR activity}

The formation of $\mathrm{NH}_{4}{ }^{+}$intermediates reflect the activation of $\mathrm{NO}$ in the presence of $\mathrm{NH}_{3}$. The proton conductivity enhancement (i.e. the difference between lis after $30 \mathrm{~min}$ in $\mathrm{NO}$ and lis after 30 min in $\mathrm{N}_{2}$, see Fig. 2a-b) has been found to be relatable to the NO reduction rate (Fig. 3). Specifically, in catalysts with low Fe-loading, where isolated or dimeric $\mathrm{Fe}$ species are predominant (verified by means of UV/Vis and XRD data), a higher reducibility of $\mathrm{Fe}(\mathrm{III})$ coincides with a more pronounced change in $\Delta \mathrm{l}_{\mathrm{is}}$, and therefore a higher presence of highly mobile $\mathrm{NH}_{4}{ }^{+}$ions. These results demonstrate that a typical gas sensing approach, i.e. the combination of IS and DRIFTS applied in situ, allows not only to observe the formation of $\mathrm{NH}_{4}{ }^{+}$intermediates, but also their favoring effect to the SCR activity of Fe-ZSM-5. The formation of $\mathrm{NH}_{4}{ }^{+}$ intermediates may serve as a potential "descriptor" for the design of active Fe-zeolite catalyst for $\mathrm{NH}_{3}-\mathrm{SCR}$.

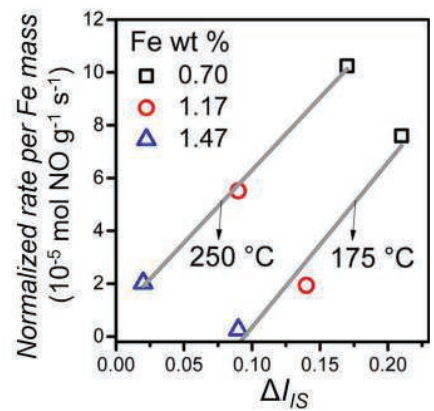

Fig. 3. Correlation between $\mathrm{NH}_{4}^{+}$intermediate formation (associated to $\Delta l_{I S}$ ) and NO reduction rates for zeolites with varied Fe-loaded ZSM-5 catalysts at different temperatures (reproduced from [6]).

\section{References}

[1] R. Zhang, N. Liu, Z. Lei, B. Chen, Chem. Rev. 116, 3656-3721 (2016); doi: 10.1021/acs.chemrev5b00474.

[2] M.E. Franke, U. Simon, R. Moos, A. Knezevic, R. Müller, C. Plog, Phys. Chem. Chem. Phys. 5, 5195-5198 (2003); doi: 10.1039/b307502h.

[3] K. Góra-Marek, K. Brylewska, K.A. Tarach, M. Rutkowska, M. Jabłońska, M. Choi, L. Chmielarz, Applied Catalysis B: Environmental 179, 589-598 (2015); doi:1 0.1016/j.apcatb.2015.05.053.

[4] P. Chen, S. Schönebaum, T. Simons, D. Rauch, M. Dietrich, R. Moos, U.Simon, Sensors 15, 28915-28941 (2015); doi: 10.3390/s151128915.

[5] C. Paolucci, A.A. Verma, S.A. Bates, V.F. Kispersky, J.T. Miller, R. Gounder, W.N. Delgass, F.H. Ribeiro, W.F. Schneider, Angew. Chem., Int. Ed. 53, 11828-11833 (2014); doi: 10.1002/anie.201407030.

[6] P. Chen, M. Jabłońska, P. Weide, T. Caumanns, T. Weirich, M. Muhler, R. Moos, R. Palkovits, U. Simon, ACS Catal. 6, 7696-7700 (2016); doi: 10.1021/acscatal.6b02496. 